cholera, never thoroughly contracts. Moreover, the smooth muscle wall sluggishly relaxes after its expulsive effort is over. This relaxation, at the same time that it produces a partial vacuum, diminishes the sphincteric contraction of the ureteral orifices, and any urine which may have collected in those passages is partially propelled by the vis a tergo of the circular muscle of the ureters and partially sucked by gravity and this negative pressure into the bladder. The aspirator consists of a small elastic ball and an oval glass bottle (see Fig. 1), which can be affixed to the end of a specially curved catheter, which latter is furnished with an elongated laterally placed eye. There are two catheters, one for each ureter. The bladder is first emptied and the catheter introduced. When it has fully entered, it is steadied and rotated over at the same time by the finger and the thumb, to the right or the left side according as the right or left ureter has to be engaged. The laterally placed eye will now be exactly over the ureteral orifice, for the angle $A$ (Fig. 1) is the same as the normal angle which the outer side of the trigone builds with the long axis of the urethra. Fig. 2 shows the instrument in place. Pressure of the right hand upon the elastic ball empties it of its air, and its stem is then affixed to the end

FIG. 2 ,

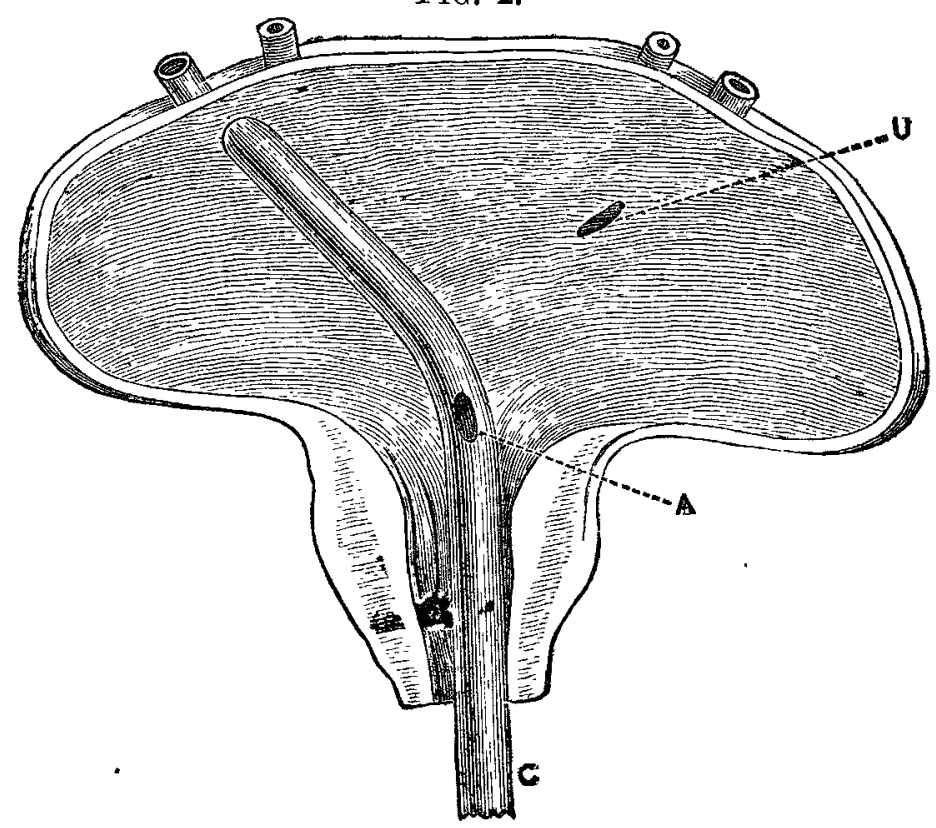

c, Right-sided aspirator in position. $\mathrm{u}$, Left ureteral orifice.

a, Opening to receive urine from ureter.

of the catheter and the ball gradually released. The air in the catheter is correspondingly exhausted and the ureteral orifice is sucked into the eye, where it can be maintained by careful management of the ball, or by gentle counter-pressure of the finger in the rectum. In ten minutes sufficient urine will have collected in the catheter for it rarely enters the glass bottle-to admit of an examination. I have lately had this catheter double channelled, so that the urine from the disengaged ureter may enter and drain off through the orifice A (Fig. 2) into a different receptacle.

I have said that it is not infallible. Sometimes there is but one ureteral orifice, as in a case I showed at the Pathological Society (1885-86). I found the ureters in another case (Path. Soc., 1886) much displaced by the action of circumureteral tubercular inflammation. Sometimes small bunches of villoid or other growth in the region of the ureters (three cases, Path. Soc., 1886) prevent close application of the eye and mislead by tinging the secretion with blood. A 20 per cent. solution of cocaine renders this slight operation painless. I have used the instrument in differential diagnosis of the site of symptomless hæmaturia, also in withdrawing scraps of growth from the trigone, and in performing an operation upon the kidney, the details of which I hope shortly to publish. The instrument can be obtained from Mayer and Meltzer, 71, Great Portland-street.

George-street, Hanover-square.

A Cenmenarian.-On the 8 th inst., at the meeting of the North Dublin guardians, Dr. Kenny, M.P., reported the death of an inmate of the workhouse at the age of 105 years. He was a sailor at the time of the Irish rebellion of 1798 , and smoked tobrcco up to the day of his death.

\section{A NEW METHOD OF}

REMOVAL OF THE ENTIRE TONGUE BY MEANS OF THE GALVANIC (OR SIMPLE WIRE) ECRASEUR AND SCISSORS.

\section{Br FERDINAND ALBERT PURCELL, M.D., M.CH.,} SURGEON TO THE CANCTR HOSPITAI.

IN my lecture given at the Cancer Hospital on Jan. 29th I demonstrated a new method for the removal of the entire tongue and floor of the mouth-applicable for removal of one-half of the organ if necessary-and presented a series of four cases operated on last year. I have christened it the "supra-hyo-glosso-epiglottidean method," which name anatomically describes the operation. The necessity for seeking for another mode for removal of part or the whole of the tongue is not that I have relinquished operating by the Whitehead or scissors method, combined with or without the preliminary tying of the linguals, or of performing first tracheotomy with the use of Trendelenburg's apparatus as used by Mr. Barker and Professor Kocher of Bern,- but that, in my experience, it may be in exceptional cases, in operating on the tongue, especially by the scissors or Whitehead method, bleeding has been the factor most difficult to combat, and its consequent result-namely, "surgical pneumonia." "Nothing is new under the sun," as the old saying goes; nor is it so in this, for Mr. Barwell so long ago as $1879^{1}$ described his method, of which mine is the offspring; and recently I was much struck by a paper on a "Method of Controlling Bleeding during Complete or Partial Excision of Tongue" by Mr. Jordan Lloyd, of Queen's Hospital, Birmingham, ${ }^{2}$ in which he applies steps of my method for the controlling of bleeding from the linguals.

With this factor--the bleeding-it is of great importance that operations should be made easy for ordinary surgeons, and as bloodless as possible for patients whose powers have been weakened by pain, from deficient nutriment arising from difficulty of mastication and salivation, and anxiety, and who, after a severe operation, and having to submit to an absence of solid food, can be expected to bear well the loss of blood. My experience of my "supra-hyo-glossoepiglottidean method" reduces our trouble from this source without any blood loss whatever, and by which is seeured a very thorough removal of the tongue, together with the floor of the mouth and all structures down to the hyoid bone. I would recommend the surgeon, as Mr. Jordan Lloyd suggests, before attempting this procedure "to familiarise himself with the glosso-epiglottidean pouch, by palpation with an index finger introduced into its deepest part and another placed outside between the hyoid bone and the under surface of the angle and rami of the lower jaw ; this anyone can try on himself; it is surprising how little tissue intervenes between the fingers, and how distinctly the various structures in relation to this space can be identified." It is necessary after removal of the tongue to have the cavity kept well drained by means of an indiarubber drain through the supra-hyoid opening, the parts dusted inside with iodoform, and the patient fed through an œsophageal tube.

The patient having been anæsthetised, first make an incision in the neck about a quarter of an inch long in the middle line from the hyoid bone forward, only skin deep; then pass a whipcord ligature through the raphe of the tongue an inch behind its tip, to hold the organ by; gag the mouth open; introduce the left index finger well to the bottom of the glosso-epiglottidean pouch, back of root of tongue. It may be necessary at this stage, so as to make room to get well round the base of the tongue, to snip with scissors the palato-glossi muscles-viz., the anterior pillars of the fauces, as also the stylo-glossi muscles of both sides; these may require pressure-forceps to be employed, as generally some small vessels may bleed; these can be taken off when wanted out of the way. Now take, say, Wood's hernia curved needle on handle, being stout, long, and well curved, threaded with medium-sized whipcord; or the needle in place of the thread may carry the platinum wire if the surgeon intends using the galvanic écraseur. Hold the needle in the right band horizontally, its concavity turned
2 Ibid., Jan. 23rd, 18:6. 
upwards and towards the neck, enter its point at the submental incision immediately above the hyoid bone, pass it through the raphe of the mylo-hyoid, the genio-hyoid, and the lower fibres of the genio-hyo-glossi muscles, and direct it to the right side, forming the sweep of a half circle; now feel for the point of the needle with the left finger as the needle is pushed through so as to enter the bottom of the side of the right glosso-epiglottidean pouch above the great cornu, hook up the loop of thread, or it may be the platinum wire, with the left finger, pull it well through and out of the mouth, and withdraw the needle; do the same on the opposite side, for which it will be necessary to change the position of the hands, holding the needle in the left and placing the right index finger in the left side; a loop will in this way be lodged in the pouch at either side; thread each loop with the platinum wire, making a hook of wire by bending its end on itself; draw on both sides, so that the ends of the wire are brought out at the supra-hyoid incision, make even and detach the loops; the centre of the wire now forms a loop and rests on the base of the tongue. Before proceeding further, remove the pressure-forceps from off the cut anterior pillars of the fauces; take the same curved needle (Wood's), unarmed this time, and enter it again at the supra-hyoid incision in a vertical manner, its concavity directed towards you ; feel for the point of the needle with the left finger as it is pushed through the centre of the root of the tongue and in front of the epiglottis ; guard the point by means of a piece of cork here the needle remains to act as a guide for the wire to travel behind; lodge the wire behind the guide and draw it taut, complete its connexions, and work the écraseur-the tongue is severed through its root in a well-defined vertical plane; withdraw the guide-needle. Secondly, free with scissor the anterior and lateral attachments of the tongue and floor of the mouth, release the organ and withdraw it through the lips. No hremorrhage, as a rule, occurs; but if the battery or the ecraseur should be worked too quickly and bleeding does take place, a sponge on a stick pressed into the furrow and following the wire will be found sufficient to restrain it ; the linguals are included and cut through by the wire, and if they should so happen to spurt, they can be secured by pressure-forceps on the stump and tied. The ordinary simple écraseur, either single wire or twisted whipcord, may be substituted in place of the galvanic. The entire tongue may be removed as described, or the one half if so desired, by scoring the dorsum of the tongue with a blunt-pointed scalpel exactly in the middle line, and dividing the tip freely down and through the middle line of the frænum; then take both threads (one having been previously passed through each tip), one in each hand, and, using the forefingers much in the same way that one would for tightening a ligature on a deep ressel, split the tongue in two halves, and free the diseased half with scissors.

CASE 1. John M- - aged sixty-two, from Hampstead Union, was admitted into the Cancer Hospital, Ellis ward, on July 29th, 1885, under my care. Three years ago he first noticed a small ulcer at the base of the tongue, which was very painful. Has been a slight smoker. Has no history of phthisis or of syphilis. State on admission: Situate at the base of the tongue, and on the right of the median line, is an irregular excavated surface with indurated edges, its base covered with a slough. The whole extent of the ulcer cannot be fully determined; it extends as far back as the root. He cannot endure the finger to be inserted in his mouth. No enlarged glands are to be felt. He suffers great tenderness on the affected side; is unable to eat; dribbles saliva; feels weak, and is feeble and broken down; has an old ulcer on his leg. The patient was placed on the operating table on Aug. 1st. The hyo-glosso-epiglottidean operation by means of the galvanic écraseur and scissors, as described, was performed; the tongue was severed at its base, behind the anterior pillars, in a well-defined vertical plane. The action of the heated wire at first was too rapid, for it had not worked very long before some blood welled up. A stick sponge was pressed in the furrow following the wire, which restrained all bleeding; this was afterwards found to have come from a small superficial vessel immediately under the mucous membrane; the linguals gave no trouble. The mouth presented a deep excavated cavity; entire floor removed. A drainage-tube of good size was passed up through the opening in the neck, and the parts were dusted with iodoform. After twenty-four hours he was fed by means of the cesophageal tube. By the end of the month he was quite healed.
CAss 2. James $\mathrm{W}_{\text {_- }}$, aged sixty-five, from St. George's Workhouse, was admitted into the Wolrige ward of the Cancer Hospital on Aug. 7th, 1885, under the care of Mr. F. B. Jessett. After operation he was attended by myself, my colleague having gone on his holiday. No history of cancer or of phthisis. Has had no serious illness. Became totally blind eleven years back. About nine months ago a pimple the size of a pea appeared on the left side of the tongue; this increased slowly. On admission there was on the left side of the tongue an ulcerated spot which could be covered with a two-shilling piece. Although it was irregular in outline, the edges of the ulcer were hard and the base uneven, being covered by unhealthy granulations. Situate beneath the extreme angle of the ramus of the right jaw a gland was enlarged, and another beneath the jaw on the left. On Aug. 11th the operation for entire removal of the tongue by the method described by means of the galvanic écraseur and scissors was performed. The gland on the left side was removed by an incision, and the wound sutured and sealed with styptic collodium. The gland of the right side was fished out of the floor of the mouth by the finger. The linguals spurted, but were seized in pressure-forceps and tied. Little blood was lost. A drainage-tube was passed up through the opening in the neck. The patient made a good recovery.

CASE 3.-Joseph $\mathrm{R}--$, aged sixty, married (from Caerphilly, Cardiff), was admitted into the Cancer Hospital, Ellis ward, on Aug. 22nd, 1885, under my care. There was no history of phthisis or of syphilis. He never suffered from any serious illness. Has been a heavy smoker. His father had epethelioma of the lip; his mother died of old age. About nine weeks ago he first noticed that his tongue was being irritated by the teeth, two of which he had removed. The tongue, however, got worse, and rapidly ulcerated. The pain was severe, and he was greatly worried by continual dribbling of saliva. On admission, the tongue was fixed at the left side; ulceration, with induration extending back to the root, engaging anterior pillar and neighbouring soft palate; glands to be felt below mastoid process; emaciation; unable to masticate any food; was suffering great pain. On Aug. 29th I performed the hyogosso - epiglottidean operation, using the wire Ecraseur (instead of the galvanic) and scissors. The patient breathed badly under the anæsthetic. When about one-third through the tongue, the forcible constriction apparently closed the rima glottidis and caused asphyxia. The écraseur was not worked while artificial respiration was being performed. The patient looked bad, but had a capital pulse at the time. I proceeded to perform tracheotomy, and had made the incision, when the patient took in an inspiration, and a second, on which I desisted. I again worked the écraseur, pressing it upwards in place of pulling on the instrument; this being completed, the wire guide was removed, the anterior and lateral attachments were cut with scissors, and the tongue, released, was withdrawn. The lingual on the left side, having spurted, was seized and tied. The specimen was examined; it was found that the disease was not all removed. Using Paquelin's cautery, the parts were freely burnt, including the surface of the jaw-bone, as also the anterior pillar of the fauces and neighbouring soft palate; this worked away the structures to a much lower level on the diseased side, and by removing a piece somewhat larger than a walnut a clear view into the pharynx was obtained. A drainage-tube was then passed through the opening in the neck, and the parts dusted with iodoform. The patient made a good recovery.

CASE 4.-Joseph $\mathrm{S}-$-, aged forty-seven, married (from St.Paul's-road, Bristol), a sailor, was admitted into the Cancer Hospital on Aug. 25th, 1885, under my care. The right side of the tongue was ulcerated; induration and fixation of the organ on the same side; remains of a recent incision; glands enlarged on left side. No history of cancer or phthisis always enjoyed good health; is a heavy smoker; usual stimulant is rum. About seven months ago he first noticed a small warty growth at the base of the tongue; this shortly afterwards disappeared. Then a lump came on the right side of the neck, the tongue became painful at the right side, and a white streak appeared. He was at the time on the coast of Africa, and was advised by his doctor to go home. He returned to Bristol and was admitted into the Bristol General Hospital, when the small growth was removed from the side of the tongue on April 2nd, 1885. After operation he suffered great pain, and on Aug. 11th the gustatory nerve was cut. State on admission: A strong healthy man. 
Opposite the first molar tooth on the right side is a fissure extending as far as the median line; beneath surface ulcerated; organ bound down to floor of mouth; one or two glands enlarged below jaw. On Sept. 1st I performed this operation with the galvanic écraseur and scissors, severing the tongue close up to the epiglottis. One lingual spurted, and was tied. Where the tongue had been adherent on the right side, the parts were freely burnt with Paquelin's cautery, a drainage-tube passed up and the parts dusted with iodoform. He was fed during the night with nutrient enemata; next morning by means of the œsophageal tube. - Sept. 7th: Temperature 101\%; some pneumonic râles; was delirious during the night.-22nd: Has passed through an attack of pneumonia; dulness still of the right side; inserted a hypodermic syringe needle into the right pleura, withdrew only a drop or two of pale fluid.24th : Situate on the right side of the floor of the mouth there is a recurrent growth of the size of a hazel-nut.Oct. 2nd: Had a copious discharge of purulent sputa; great fetor of breath ; evidently an abscess of the lung has burst.3rd: Had a rigor this morning; temperature $1026^{\circ}$; right side of the chest fuller than the left. To inhale iodine vapour.

The patient eventually recovered. I had him again anæsthetised, and with Paquelin's cautery freely cauterised the floor of the mouth, destroying the recurrent growth. He afterwards made a good recovery, and left the hospital about Christmas. My patient replied to a query that appeared in Tit Bits as follows:-"Sir,- - Re question 1926 of Nov, 21st, 1885 , it may be interesting to your readers to know it is quite possible to talk without a tongue. The writer has not a particle of tongue remaining, as it was removed recently at this hospital on account of cancer. I may add I still retain a sense of taste and enjoy a capital appetite. I shall be pleased to answer any further questions on this matter, and if you think fit to publish this you are quite at liberty.-Yours, \&c., Captain SWolrige ward, Cancer Hospital, S.W."

\section{PARALYSIS DEPENDING UPON IDEA.}

BY C. W. SUCKLING, M.D. LoND., M.R.C.P., PHYSICLAN TO THE QUEEY'S HOSPYTAL, BIRMTYGHAM.

IN the Birmingham Medical Review for June, 1885, I published an account of a boy who had suffered from paralysis of one leg for two years, and whom I was able to cure immediately after making the diagnosis of paralysis depending upon idea. Since then $I$ have met with three other cases, two of which were men. In one case there was complete anæsthesia of the hand; in another hemi-analgesia with localised and severe headache. In the four cases I have now seen, an accident occasioning slight injury was the exciting cause in each. All four cases were rapidly cured. Dr. Russell Reynolds, I believe, first described paralysis depending upon imagination. There is no malingering in these cases, but the patients are firmly convinced that they are suffering from paralysis. If the confidence of the patient be gained, an immediate recovery follows when he is told that he will be well immediately, the iclea being got rid of. In making the diagnosis it is important to bear in mind the two classes of people in whom functional nervous disorders are met with-the neurotic and the hysterical; the features of which have been so graphically described by Dr. Clifford Allbutt in the Gulstonian Lectures for 1884 . It is the neurotic that is apt to be affected by these paralyses depending upon idea, and it is these cases that are instantly cured when the diagnosis is made. The hysterical patient is cured with difficulty and frequently relapses; the neurotic does not relapse. The neurotic individual is vivacious, good-tempered, unselfish, intelligent, active and industrious, anxious to be cured, and grateful for recovery. The hysterical individual is listless, apathetic, lazy, selfish, with characteristic expression, not usually anxious to get well or thankful for recovery. The following is the fourth of these cases of paralysis depending upon idea that I have met with during the last twelve months.

Sarah F-_-, a widow, aged forty-six, was sent to the Queen's Hospital, to be admitted under my care, by Dr. Middleton, of Harborne, on the 15th of March last, and was discharged well on March 28th. She has led a very industrious life, having supported her five children by needlework since her husband's death ten years ago. On Oct. !th, 1885, she tumbled downstairs, falling down twenty-one steps on to her back. She was much hurt and "dazed" and very much frightened, thinking every bone in her body was broken. She walked about atter the accident for a day or two, but suffered from pains in the back, down the legs, and round the body; these pains were intermittent, very severe, and lasted altogether three weeks. Two days after the accident she took to her bed, and a day or two later found that she was paralysed in both her legs and had lost all feeling in them. Since the accident she had suffered from constant headache and backache. Upon examining her I found that she had a little power over the legs, but very little. Slight ankle-clonus could be elicited on the left side. The plantar and abdominal reflexes were lost, but the knee-jerk was well-marked. There was complete analgesia and thermal anæsthesia in both legs up to the knees. She was unable to localise tactile sensations below the knees, the anæsthesia not being complete. When touched with a sharp-pointed instrument she said she felt as if she were being pushed. Muscular sense was unaffected. There was superficial tenderness over the lower dorsal spines, but no pain on firm pressure or on percussion, and no irregularity of the spine. The bladder and rectum were unaffected, and I was informed by Dr. MIiddleton that she never lost control over the bladder, nor had any sign of bedsore during her illness. There was no edema of the legs, no alteration of temperature, and no change in the colour or aspect of the skin or nails. In fact, there were absolutely no trophic changes whatever. The response of the muscles to faradisation of their nerves was normal, but there was considerable electrical anæsthesia. In summing up the symptoms present, 1 of course observed their incongruity if we supposed the case to be one of myelitis, or, in fact, as due to any organic lesion. If the ancsthesia were due to actual lesion of the grey matter, how could the bladder and rectum escape? How was it that there was no sign of bedsore, no cedema, or other trophic change, such as muscular wasting? 1 diagnosed the case immediately as being purely functional, and, the woman being of the neurotic type, as paraplegia depending upon idea. I at once acted upon this diagnosis, and told the patient that I should give her the battery, which I said would at once remove the loss of sensation and enable her to move her legs as well as she ever did. She was delighted to hear this, and after a minute's faradisation sensation was completely restored, and she had full command over her lege. I then told her that on my next visit I should expect to see her walking about the ward, for I was sure that she would be able to do so. I instructed Mr. Whittendale, $\mathrm{my}$ house-physician, to see that she got up after I left, and to apply the faradaic current whenever she displayed any hesitancy. On my next visit, two days later, I found her up and able to walk and run about the ward perfectly well. She was quite delighted at her recovery, and had been most industrious with her needle since getting up. She expressed deep gratitude, and hoped to be able to repay our kindness. I may add that 1 saw my patient on the 14 th of the present month (September), and she was remaining quite well.

How was the cure effected in this case? Undoubtedly, I think, it was by the mental state of faith or expectation, or both, on the patient's part. She fully believed what I told her, and thus I was able to remove the idea she had that she was paralysed. The essential thing, then, in these cases is to make a correct diagnosis, and then the patients can safely and with success be told that they will quickly recorer. Now, had this been a hysterical woman, I should in all probability have failed to cure her, or, at any rate, the cure would have been more tedious. I recently had a woman under my care suffering from locomotor ataxy with hysterical anæsthesia. For two years I did all I could to cure the anæsthesia, and failed; but when she left the infirmary she applied leeches to her legs and returned with the anæsthesia gone. Isolation, so useful in hysterical cases, is not needed in these.

In the same ward with my case of ideal paralysis there was a young woman suffering from hysterical neuralgia, and the contrast between the two patients was very marked. The hysterical woman was listless and apathetic, did not manifest any desire to be cured, and would scarcely allow that she was any better than when admitted. When told that she was well enough to go back to her duties as a 